Article

\title{
Remote Design and Manufacture through the Example of a Ventilator
}

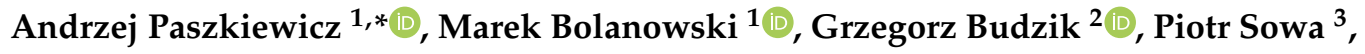 \\ Tomasz Pisz ${ }^{3}$, Mariusz Oleksy ${ }^{4}$ and Łukasz Przeszłowski ${ }^{2}$ \\ 1 Department of Complex Systems, The Faculty of Electrical and Computer Engineering, Rzeszow University \\ of Technology, Al. Powstańców Warszawy 12, 35-959 Rzeszów, Poland; marekb@prz.edu.pl \\ 2 Department of Machine Design, The Faculty of Mechanical Engineering and Aeronautics, \\ Rzeszow University of Technology, Al. Powstańców Warszawy 12, 35-959 Rzeszów, Poland; \\ gbudzik@prz.edu.pl (G.B.); lprzeszl@prz.edu.pl (Ł.P.) \\ 3 InfoSoftware Polska Ltd., ul. Przemysłowa 5, 35-105 Rzeszów, Poland; psowa@infosoftware.pl (P.S.); \\ tpisz@infosoftware.pl (T.P.) \\ 4 Department of Polymer Composites, Faculty of Chemistry, Rzeszow University of Technology, \\ Al. Powstańców Warszawy 6, 35-959 Rzeszów, Poland; molek@prz.edu.pl \\ * Correspondence: andrzejp@prz.edu.pl
}

Received: 6 May 2020; Accepted: 19 June 2020; Published: 20 June 2020

Featured Application: The proposed model and architecture can be used to build virtual prototyping laboratories, taking into account geographically distributed human, manufacturing, and measurement resources, which will be seen as one coherent cyber-human system. This will accelerate the time needed to develop a prototype and reduce the cost of its production.

\begin{abstract}
In this paper, the authors present a completely new approach to the remote prototyping process, taking into account the distributed nature of design and manufacturing resources. A new model is suggested, taking into account the conditions of the Industry 4.0 concept, along with a component of remote implementation and coordination of operations. On the basis of this model, the architecture of the target system is developed, which is further built and implemented in the actual productive environment. The system's functionality additionally enables the implementation of the design and production process in critical conditions resulting from natural disasters or epidemic states. The practical application of the developed solutions is presented on the design of a ventilator, which is dedicated to help in the fight against epidemic states, e.g., coronavirus.
\end{abstract}

Keywords: industry 4.0; rapid prototyping; 3D printing; computer systems; computer networks; cloud computing; Ventilators

\section{Introduction}

The development of the global economy, which has been observed for a while now, is conditioned by technological progress. It creates multiple opportunities, as well as numerous challenges, such as shortening the product's life cycle, reducing costs, and the control and monitoring of design and manufacturing processes, but also recycling, increasing competition, access to dispersed resources, etc. Thus, the accompanying conditions enforce a change in existing habits or business models. The related processes are a part of activities aimed at the implementation of the Industry 4.0 concept [1-3]. Therefore, one of the important aspects of the fourth industrial revolution is the integration of dispersed resources in order to increase efficiency, reliability, as well as design and production potential. The development of models and frameworks adequate for this concept, and their implementation in the real environment, is possible thanks to the popularization of automation 
technologies, global communication, computerization, but also thanks to the provision of universal standards and mechanisms of cooperation between devices, people, and various companies and organizations. The possibilities related to this can and are used both in standard design and production processes related to conducting research, conducting business activity, and also in difficult and critical conditions of society and economy, such as natural disasters or epidemic diseases.

The initial assumptions and initial models for the integration of production resources with the use of ubiquitous communication technologies were developed and presented in the 1990s, and were developed further. They established the foundations for further development of the so-called "Smart Factory". An interesting, comprehensive approach relating to the new paradigm for product design and manufacturing via ubiquitous computing technology is presented in this paper [4]. The authors propose a conceptual framework taking into account the entire life cycle of a product, beginning with its design and ending with its recycling. However, these assumptions are very general and only reveal the great potential of the idea of collecting data and information from various sources (suppliers and production equipment). A more detailed approach to this model appeared in [5], in which the authors point out the need to ensure a high level of standardization of communication mechanisms in order to integrate equipment from different manufacturers. This study focused primarily on wireless communication solutions, using, e.g., RFID technology to transmit information. Similarly, in subsequent papers [6,7], wireless communication systems, such as $\mathrm{WiFi}$, automatic identification sensors, as well as wireless information and GSM were indicated as the basis for implementation of the new manufacturing model. Another aspect of these concepts were ubiquitous production systems and enterprises (UPSE) proposals which were based on two areas: ubiquitous computing systems and virtual and networked enterprises and organizations [8]. Yet others presented the issue of ubiquitous manufacturing from the perspective of customers' access to web services that enable the use of specialized applications and services for monitoring as well as analysis of production equipment operation $[9,10]$. These approaches, although focused on the idea of the Smart Factory or Factory of Things, assumed a high level of unification, which was associated with the aspiration to create homogenous environments. Additionally, the presented models and solutions only address the aspect of integration of hardware resources, which, in the contemporary concept of the Internet of Everything, is a major limitation. In the case of developing new products, creating innovative concepts, it is very crucial to provide opportunities for the exchange of views and cooperation between geographically dispersed people. This form of integration of human resources was not included in these models. On the other hand, thanks to the modern capabilities of communication technologies, high-class specialists and experts can cooperate within different teams, including creating interdisciplinary teams focused on the development of new technologies, products, and services [11]. Therefore, in this paper, the authors have proposed the integration of design and production processes on the basis of cooperation of specialists who are far away from each other and perform their tasks on the basis of a dispersed heterogenous design and production environment.

This article focuses on one of the stages of product development, namely the rapid prototyping process. A unique feature of this process is the flexibility of the working environment of the team, which in many cases must be built on an ad hoc basis in order to meet current needs. These needs are met by the possibility of integrating individual elements that form the prototyping environment through dispersed IT systems. From the point of view of the remote work of the distributed prototyping system, this process has been called remote distributed rapid prototyping (RDRP), it has been described in [12]. Initially, the main resources that were integrated in the RDRP process were people. They cooperated remotely in the area of developing ideas, projects, or CAx (various Computer Aided systems) projects [13]. The efficient use of human resources does increase the quality of projects. An exemplary analysis of this issue was presented in [14], referring to the Cooperation on Manufacturing IT Project. However, the growing popularity of IoT and IoE solutions [15-18] enforced the need to add more resources, such as cameras, measuring systems, specialized laboratory workstations, etc., to the remote prototyping infrastructure. The process of the development of these systems is presented in Figure 1. As can be observed, the 
next stage of evolution are so-called cyber-human systems (CHS) [19-21]. At first, research on these types of systems was carried out in order to use the possibilities of technology (mainly information technology) for the purpose of increasing human capabilities. In this article the authors developed this concept and defined it as a system integrating human and computer resources in order to increase the potential of developing and producing a new product. These systems include solutions in which IT tools support the decision-making of employees at the manufacturing stage. These systems can be regarded as an evolution of CHS systems, in which a man and a machine can be seen, from a process point of view, as equal resources and the flow of data, and then information, contributes to the knowledge which enables more accurate decisions in terms of design and manufacturing efficiency. From this perspective all resources represent a valuable source of information and can contribute to the optimization of the prototyping process while IT systems, including artificial intelligence, machine systems, or other advanced solutions, support this process. At this very moment we are on the borderline between cyber-human RDRP systems and IoE RDRP systems and it is not easy to indicate the full implementation of the entire IoE RDRP process.

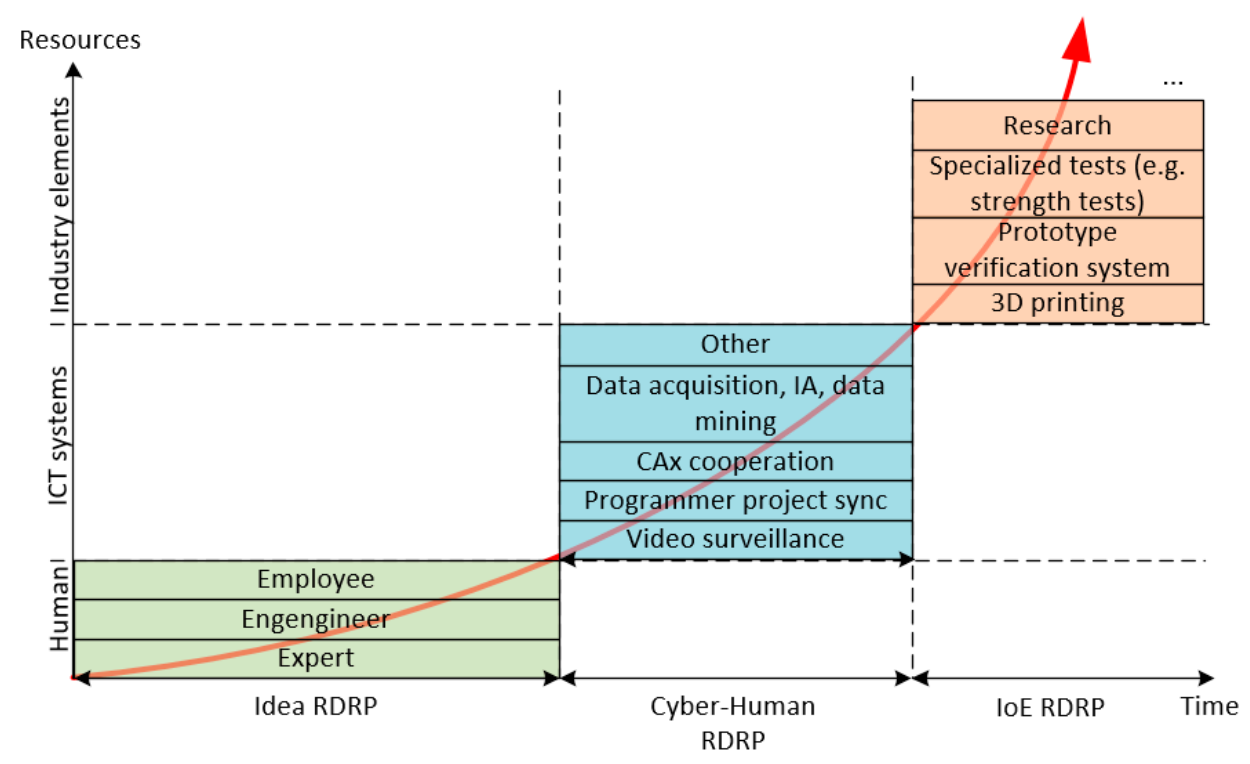

Figure 1. The evolution process of RDRP systems.

Further analyses of remote prototyping systems, performed to illustrate the current state of knowledge, have shown that currently available systems usually have a rather static architecture dedicated to solving one class of problems [22-24], or take the form of extensive conference systems [25]. In this paper [26], a cloud-based remote virtual prototyping platform for embedded control applications was proposed, which allows one to prototype application code for a large number of users with the use of simulators. Similar solutions can be found in [27]. Both solutions are designed mainly for didactic purposes. Canavan et al. [28] presents a remote audio digital signal processing prototyping system with the ability to verify the obtained effects on remote or locally connected PYNQ systems-on-chip (SoCs). Brzoza-Woch et al. [29] presents a prototype of the rapid embedded systems prototyping architecture, which supports the process of remote design of embedded systems and their monitoring. A remarkable solution was presented in [30], which organizes the rapid development of embedded human-in-the-loop cyber-physical systems process in the form of a framework, which allows one to integrate further resources within the design process. This solution can be extended yet its main purpose is related to HiLCPS systems. An entirely separate class of solutions are laboratories shared remotely, which can be used, e.g., for remote design of digital systems [31], or robot control systems [32]. Of course, further examples of remote prototyping systems can be multiplied [33,34]. Nevertheless, they have a common feature-they are dedicated to solve a specific problem. In the majority of 
cases, however, they are connected with prototyping solutions from the area of ICT, robotics or even digital systems. From the perspective of the matter discussed in this paper concerning prototyping on the basis of incremental methods, the analysis of solutions available on the market and scientific works shows that currently only systems integrating selected manufacturing and human elements are accessible, often in the environment of homogenous ownership or field structure. For instance, $3 \mathrm{D}$ print resources can be shared using 3Dprinteros [35] or related systems [36,37]. However, they neither integrate human resources nor offer measurement systems and possibilities of integrating new resources other than printers. High functionality but little (or none at all) flexibility is offered by solutions implemented in production systems, which integrate a wider range of devices, but in the form of static production lines dedicated to data production, strictly defined components.

Needless to say, the implementations presented and available on the market can be adapted to create individual components of the model and architecture presented in this article, e.g., in terms of communication, operational safety [38], etc. However, it is necessary to develop an open model for the integration of resources into RDRP processes to enable a given team to quickly solve the problem and prepare a prototype. In 2019, the authors began research aimed at the best possible integration of industrial resources used in particular in the process of prototyping elements for the aviation industry. In March 2020, human contact opportunities were reduced within the EU due to the SARS-CoV-2 virus epidemic. The need for fully remote prototyping systems involving different human and industrial resources has become a reality. The functioning of all critical elements of the IoE RDRP class system has been laboratory verified and the research on the development of the IoE RDRP model and architecture has started. An immediate opportunity to test the proposed solution has been provided by the need to develop a simple 'last resort' ventilator under the conditions of epidemiological limitations caused by SARS-CoV-2. An interdisciplinary team, consisting of engineers and scientists employed by various entities, has been established with the aim of producing a prototype. All the manufacturing machines and test stands have been made available to the team in order to carry out a rapid ventilator prototyping process. It shall be emphasized that due to epidemic limitations, the team members could only contact each other remotely. The team consisted of representatives of specialized laboratories of the Rzeszów University of Technology and companies with manufacturing, processing and measuring machines. The iS Rapid system was selected to carry out the described experiment, which was created and maintained by InfoSoftware Polska Ltd. ul. (Przemysłowa 5, 35-105 Rzeszów, Poland). It is the only tool that provides the required flexibility to integrate various types of production tools and human resources.

Due to the experience gained during the work related to the remote sharing of resources, the time to create a cooperation platform, based on the proposed model, was reduced to barely five days. The model and architecture of the remote prototyping systems will be presented in the further part of the article. What will also be presented is the functioning of the system on the example of the ventilator design process.

In this paper, the authors presented the model as well as the architecture of the remote prototyping system in accordance with IoE RDRP assumptions, which enable the realization of the process of rapid prototyping. Subsequently, an example of their application was presented to create the iS Rapid system, which was used to develop and produce a prototype of a ventilator to fight epidemic outbreak effects.

\section{The Model and Architecture of the Remote Prototyping System}

The functionality of the remote prototyping system ought to meet modern challenges and expectations of its target users. Hence, the prepared model should combine a wide range of functionality with intuitive operation, taking into account the scalability, as well as reliability and high security level. Unfortunately, models of design and production systems, which have been used so far, had referred to two classic approaches. The first one assumed that all necessary resources are located in one place and such a model had a centralized nature. In the second one, the distributed nature of resources was assumed, however, assuming their individual and independent character. Of course, the last decade has 
broadened the view on remote, distributed work in the form of the development and implementation of cloud computing models, but mainly all their implementations were related solely to IT systems. Yet the actual implementation of the Industry 4.0 concept [39] requires an unconventional view not only of local design and production resources in terms of their automation and computerization, but also requires breaking down barriers by recognizing that integrated infrastructure may not have geographical limitations.

The principles of the RDRP presented in the introduction were the basis for the development of a new model and then an architecture for the integration of distributed resources with different characteristics and purposes. This approach is particularly important in the case of distance limitations, unusual events and natural disasters or even the epidemic state. The team has thereby adopted a new model that allows design and production without time and geographical limitations. The concept of this model is presented in Figure 2.

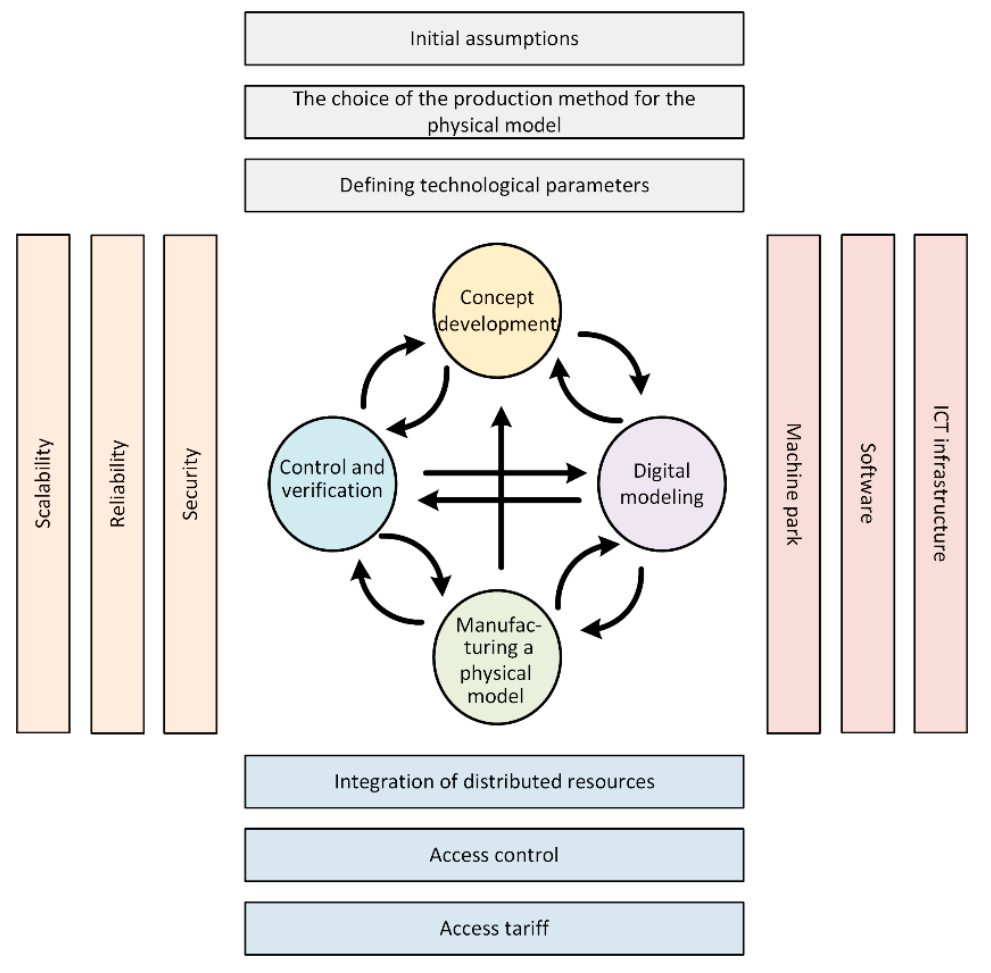

Figure 2. The adopted model of remote and distributed prototyping system.

The adopted model implies four main action stages and four functional areas supporting them. Separate action stages are correlated with the process of rapid prototyping and include:

- Creation of a concept: This is the first stage, during which initial assumptions are made about the future solution, its functionality and technical parameters, as well as its intended purpose.

- Creation of a digital model: Within this stage a digital model is developed using dedicated CAx applications. At this stage, the data concerning the modelled object should be initially verified. This allows for adjustments to be made to the initial assumptions obtained at the concept development stage. Any actions taken at this stage may save time and reduce the costs of future revisions. As for the incremental production, CAD/STL/RP numerical data is required for test models. Additionally, the choice of incremental method ought to be analyzed in terms of manufacturing process parameters, expected area of application (RP, RM, RT), and material selection. Development of numerical data can be divided into several stages. The first stage is to develop 3D geometry-CAD of the test model in the selected environment. Each 3D-CAD geometry creation software saves data with a selected software-specific file format, e.g., saving 
solid geometry in Autodesk Inventor occurs with the IPT format. However, other software on the market provides the ability to read as well as edit a file with a format other than the one dedicated for your chosen software. In many cases, however, to help multiple users working on a single test model, a file is saved in the standard ISO STEP data exchange format. The next stage is the processing of data into an incremental process. It involves superimposing a grid of triangles on the received solid models (tessellation or triangulation). With the use of 3D-CAD solid models as a base, the models with the format recognizable by software dedicated to the machine and incremental method need to be developed. The STL (Standard Triangulation Language) happens to be the most frequently used format so far. Recording the geometry in the form of a triangular grid with the above mentioned formats. It allows for the next stage of data processing, which consists of transforming the geometry into a control program for the machine. This stage is performed with the use of dedicated or supporting software and includes cutting the model into layers and defining the manufacturing parameters of the process, and then converting it into G-code. After generating a G-code, the file saved in this way should be transferred to a properly prepared device and the incremental manufacturing process should be started [40-42].

- Creation of a physical model: At this stage the design concept is implemented in the form of a physical object. This stage is accompanied by a set of activities aimed at precise determination of technological parameters, selection of devices from the machine park and their calibration, etc.

- Control and verification is carried out in order to analyze whether the obtained component meets both the assumed quality parameters and expectations with regard to functionality.

As presented in Figure 2, the relations between individual stages are in most cases bidirectional, i.e., the future solution should enable the return to previous stages in order to introduce corrections, improvements and modifications. Such an approach is consistent with the spiral model of the life cycle of a technical and technological project for industry 4.0 [43].

The developed model also implies 4 functional areas, which are not directly connected with only one stage of operation. This is due to the fact that in most cases they apply to all stages. The first group includes functionality related to defining, discussing and specifying initial project assumptions. These activities are often accompanied by a "brainstorming" and are connected with relations between many team members or teams. Within this group, the choice of the physical manufacturing method is also distinguished. At this point, it should be emphasized that currently there are many methods of physical production of objects in the process of rapid prototyping [44-46]. These methods must guarantee the results that are consistent with the initial assumptions. Furthermore, they require proper definition of technological parameters. The second functional group consists of basic elements of widely understood infrastructure including: ICT infrastructure, software, and full machine park. These elements are necessary for the proper functioning of the remote prototyping service based on a distributed system. This group includes both efficient servers, disk arrays, high-performance computer network, general and specialist software, manufacturing machines and equipment, as well as hardware control and supervision elements. The third functional group refers to providing coherence of operation of the whole system through integration of distributed resources, as well as access control and tariffication. This functionality must take into account different levels of access to different system resources located in different locations, companies, institutions and universities. Access to individual resources must be in accordance with the security policy and level of authorization adopted, or the purchased or split tariffication/license. The last functional area shall include all methods and means to ensure scalability, reliability, and security of system operation. They shall provide for the system to be used at local, regional, national or even international level. The model itself does not impose any specific solutions and mechanisms, as technological development in this area is very fast, and what is more, it is in line with the latest developments relating to the principle of openness of systems.

When adapting the presented model (Figure 2), before developing the targeted system architecture, it is necessary to take into account the rapid prototyping process, the outline of which is presented in Figure 3. 


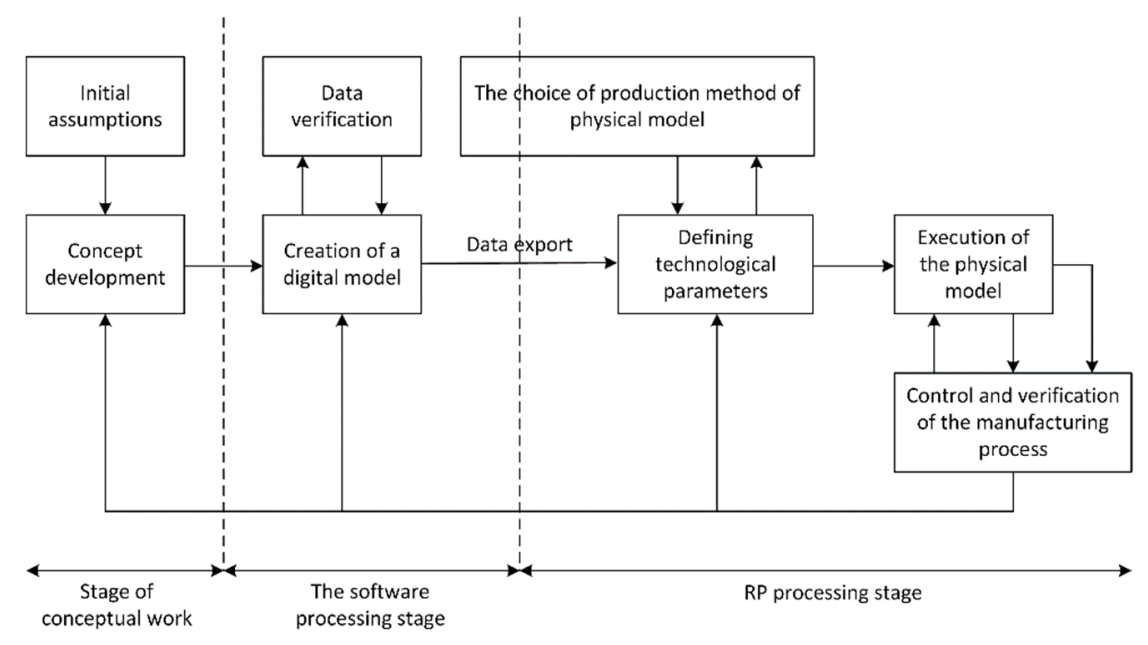

Figure 3. Diagram of the rapid prototyping process [12].

This diagram illustrates the process of rapid prototyping. It is important that the adopted model is complementary to it. As a result, the management and design-creation relationships will be consistent with each other, which will contribute to their proper performance. Up until now, this process was usually carried out within one company. The selected elements of the process were, of course, implemented in another institution, but independently and were not connected with each other using a coherent hardware and software infrastructure. It should be stressed that each of the components of the whole process plays an important role in it. Therefore, the aim of developing a proper system architecture supporting the process of rapid prototyping in a distributed environment, while providing remote access to resources, shall take into account the modern, convergent ICT infrastructure in the form of, among others, a high-performance computer network.

The principles presented above, resulting from the adopted model and the defined process of rapid prototyping, constituted the basis for the development of the target system architecture, which is presented in Figure 4.

The presented architecture is based on the possibility of remote prototyping. Thus, the main assumption was the ability to remotely share resources located in different places. These resources can include both the environment for teamwork, exchange of ideas and creation of design assumptions, but also the environment of specialized and dedicated software used at the different stages of prototyping, as well as individual devices and entire machine parks. This architecture's core is based on a proprietary software model based on cloud computing with fog computing elements [47]. This solution focuses on key functionality including two basic layers: the analytical layer and the network services layer. In the case of the first one, the implementation of expert systems [48], artificial intelligence and machine learning mechanisms [49-52], as well as own knowledge bases is assumed. These solutions support the decision-making processes [53]. It is also assumed that experts can actively participate in them. The second, equally important, layer consists of ICT systems and software such as: CAD applications, resource virtualization systems, access control systems, planning and tariffication systems, etc. Operation of this architecture would not be possible without the communication layer, based on an efficient network infrastructure, as well as the layer of ICT equipment such as: servers, disk arrays, etc. 


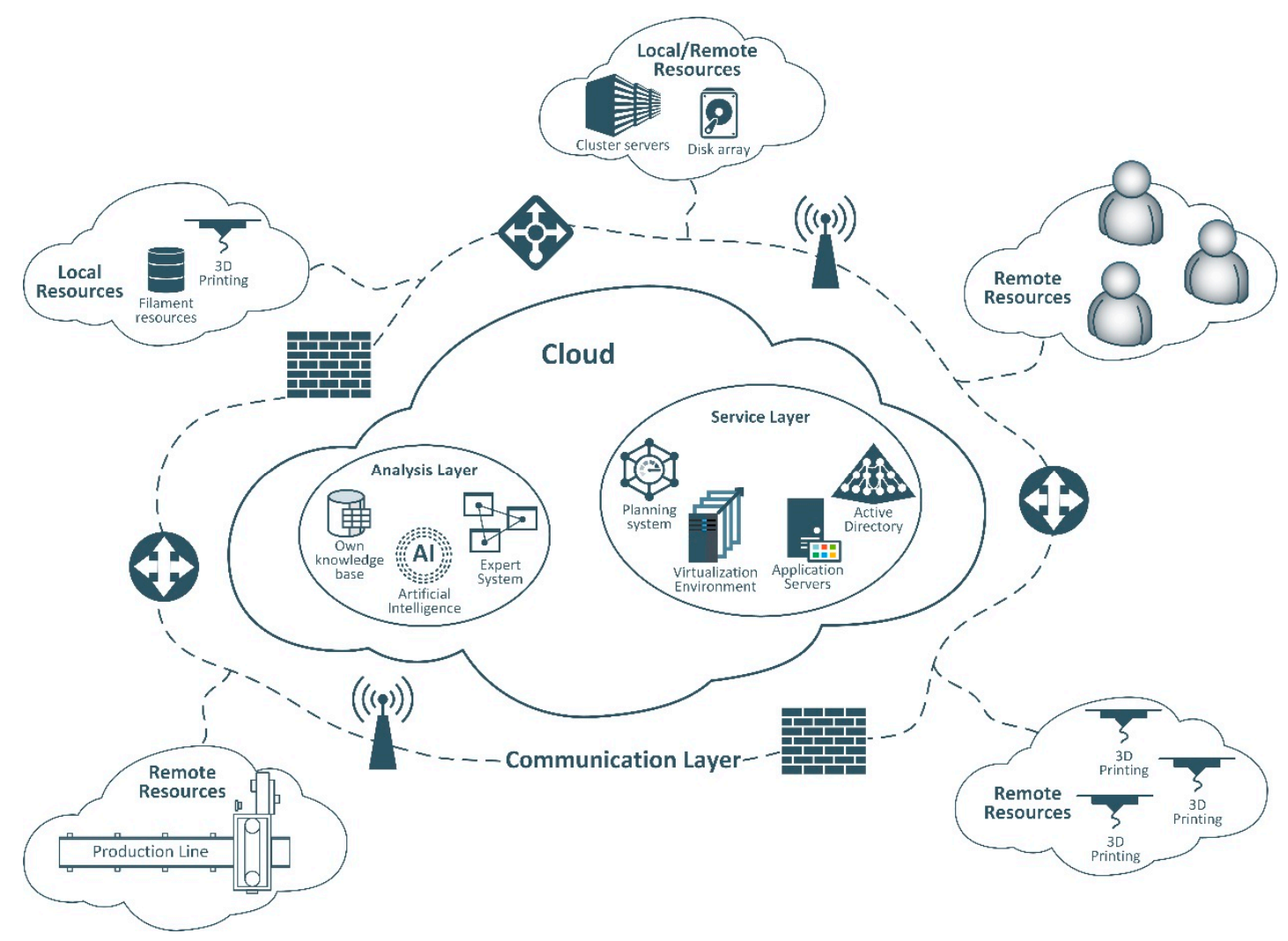

Figure 4. Remote prototyping system architecture.

Under the proposed model, autonomous areas containing remote resources of customers or end partners have been designated. It is the owner of the "Remote Resources" cloud (RR) who sets the rules for making its resources available, creates an access interface to them and ensures their security. Many companies have well-proven methods and systems to form and work with their resources. The only thing they usually have to do is to prepare a manual describing the rules of using their resources. Essentially, during the integration of manufacturing resources in the proposed model, we have established three architectures for sharing resources by companies:

1. Providing real-time access to the device by offering access to software that directly controls the device. For this task, Remote Desktop connections were used on a computer connected directly to the machine. Another way of achieving it was to create ad hoc virtual machines with a specific set of control software or tools on the machine which, using specialized cards, was connected to many production machines.

2. Providing specialized production and laboratory resources on a pseudo-batch processing basis. In the central cloud a task dedicated to a specific RR cloud was harmonized, allowing the employee's time as well as machines to be booked for a given task at a given time. In the course of its execution, the employee was able to contact the customer in order to clarify the production parameters, testing process, etc.

3. Sharing production resources through programming interfaces (e.g., RestAPI) or direct access to the device was made available via TCP/IP protocol.

In the proposed cloud model, the central cloud is responsible for connecting resources within a given project group, to which it provides rules of access to individual resources, manages directory services, provides access to data repository services, creates a communication platform for the team, and conducts the acquisition of data downloaded from machines. Within the resources of the central cloud, it is possible to implement a given number of virtual machines on which specialized design software or analytical systems (artificial intelligence, Big Data, etc.) can be installed. One of the 
most important functions of the system is a system of harmonizing tasks and managing the flow of semi-finished products and results of engineers' work. This approach allows to coordinate the work of all resources in the asynchronous mode, which results directly in the acceleration of prototyping work. This ensures high flexibility and heterogeneity of the architecture, in contrast to the existing solutions [54-57]. Further complication of the model and, consequently, the architecture decreases its usefulness and hinders implementation in the real environment. What is essential is that the entities can make their resources available by moving from a pseudo-batch processing architecture to more complex architectures as their machines are more widely used.

Based on the proposed model, the architecture presented in Figure 4 was implemented by InfoSoftware Polska Ltd. With the support of the scientific staff of the Rzeszów University of Technology. As a result of the research, engineering and implementation work, the iS Rapid system, which enables remote prototyping and sharing of design and production resources, was created. The system is based on a cloud computing, which facilitates access to its resources and ensures its scalability with the growing demand for larger resources from users. Due to the involvement of specialists from various fields, functionality from all layers has been integrated: physical, communication, application, and analytical services. iS Rapid enables remote prototyping and production of both individual tasks as well as teamwork nature. The available machine park has been integrated with the database, which supports the users in the process of selecting appropriate design and manufacturing parameters. The whole system provides the user with control and monitoring of individual activities both at design and manufacturing stages. Additionally, resources of cooperation between dispersed team members have been made accessible. Thus, an actual distributed environment for rapid prototyping based on remote access was implemented.

\section{Model Comparison}

A number of models and architectures, integrating manufacturing elements and human resources in the prototyping process, were used in the course of work on prototyping elements that preceded the development of the presented RDRP system model. Once again, it shall be emphasized that the discussed process of rapid prototyping is based on resources heterogeneous from the point of view of properties, i.e., the working environment is created by people and machines belonging to various entities, which have different properties. In the simplest, classical model, the integration of resources was based on sharing design files and human resources. In this approach, it was necessary to organize and coordinate team meetings and production work. This model is still used in many companies, but its main disadvantage is a very long period of project work. This is due to the need of synchronizing many people's work schedules and availability of resources of various entities for the project team. At the start of the process, the model's purpose was taken into consideration, but the team estimated the duration of prototype development to last for 100-150 days. For this reason, among other things, this model was not chosen as the targeted one for the ventilator production.

In the second stage, the application of the cloud manufacturing (ubiquitous manufacturing) approach, described in $[4,5]$, was considered. The team already had some experience in this area, in particular in its use for the development of cyber-human systems (Figure 1). In systems of this type, the paradigm of cloud in the IaaS (Infrastructure as a Service) model known from computer solutions, researchers and engineers attempt to transfer to the environment of manufacturing machines, omitting the utterly different nature of the industrial environment. Difficulties in the implementation of this class of systems are recognized by multiple authors of scientific papers within this field, who jointly confirm the low interest in the direct implementation of this class of systems, even in the academic environment [4]. In one of the projects, related to the aviation industry, the team undertook the implementation of the idea of cloud manufacturing in the environment of several companies. Unfortunately, this class of system requires a very strong standardization of all processes, communication interfaces, types of project files, and IT management systems. The process of standardization and unification of access to systems' diverse ownership and properties takes a very 
long time and is extremely costly. The final cost and time needed for the preparation depends on the number of entities involved and the complexity of the structure of production machines. In fact, this model allows for the integration of resources in each of the stages indicated in Figure 1, although, due to the time of preparation works, it is applied in the case of static long-term cooperation between manufacturing entities. These entities may share resources with each other or make integrated resources available to external customers by offering them access in the cloud manufacturing model. Using this model in order to make resources available quickly and flexibly in the RDRP process is simply impossible. The team estimated that it would take approximately one year to integrate the resources in this model for ventilator manufacturing, which would include adequate staff training.

Table 1 illustrates the comparison of the proposed model with the classical model and the cloud computing model from the point of view of applying it to the creation of RDRP systems. The comparison assumes that the basic architecture of the system, built on the basis of a given model, has already been implemented and a new group and new resources are being created as part of the work.

Table 1. Comparison of model-specific features with regard to RDRP with "last resort" ventilator development as an example.

\begin{tabular}{|c|c|c|c|}
\hline & $\begin{array}{l}\text { Classic } \\
\text { Model }\end{array}$ & $\begin{array}{c}\text { Cloud Manufacturing } \\
\text { (Ubiquitous } \\
\text { Manufacturing) }\end{array}$ & Proposed Model \\
\hline $\begin{array}{l}\text { The time needed to produce a prototype } \\
\text { in a given model }\end{array}$ & 100-150 days & 1 year & 5 days \\
\hline Scalability & Large & Very large & Large \\
\hline $\begin{array}{l}\text { Average time for adding new production } \\
\text { resources }\end{array}$ & N/A & 3-5 months & 1 day-2 weeks \\
\hline $\begin{array}{c}\text { Supporting work in relations to TRL } \\
\text { levels }{ }^{1}\end{array}$ & $1-9$ & $6-8$ & $1-9$ \\
\hline Resistance to cyber attacks & Very high & High & Low to medium ${ }^{2}$ \\
\hline Diagnostics and problem response & Very fast & Medium & Fast \\
\hline Implementation potential in SMEs ${ }^{3}$ & High & Very low & High \\
\hline
\end{tabular}

${ }^{1}$ TRL-Technology Readiness Levels, ${ }^{2}$ depending on the individual cloud operators $R R,{ }^{3}$ Small and medium-sized enterprises.

\section{The Use of Is Rapid in the Development of a Ventilator}

Recently, new conditions, or rather challenges, have emerged and are directly related to the outbreak of SARS-CoV-2. As the epidemic escalated, the lack of personal protection resources and elements supporting medical processes has become increasingly noticeable. The analysis of the situation in Poland and Europe has shown that one of the critical medical resources are ventilators. The research team decided to use the created solution to quickly design, manufacture, and launch a "last resort" ventilator. The name reflects its purpose in a rather positive way. The aim was not to develop a competitive product that would live up to the highest medical standards, but rather to provide a solution to support people infected with coronavirus and people having respiratory difficulties in extreme circumstances. Such a solution may be particularly useful in the situation of an extremely high number of infection cases and the resulting lack of professional equipment. Additionally, a potential method of making use of such a device is to support patients in places located far away from specialized medical care facilities while they wait and during transport. In order to properly approach such a challenge, it was necessary to mobilize and cooperate between scientists and specialists in various fields such as: machine construction, material science, information systems, as well as representatives of various companies and suppliers. Taking into account the travelling and gathering restrictions, due to the current state of the epidemic, the best solution was to use is Rapid. The implementation of the developed architecture, that was based on the is Rapid system, included the physical layer, application layer, communication layer, and analytical layer. The physical layer consists of both manufacturing devices (3D printers) as well as servers, cameras, etc., deployed 
in various locations. The communication layer consists of Internet connections, as well as network infrastructure connecting manufacturing equipment and servers. The application layer is the whole environment based on the virtualization of resources, which include systems of virtualization of IT resources, prototyping process control systems, task queuing system, access control system, system supporting the design as well as modelling of objects and group work system. The analytical layer includes a repository of data collected remotely (including information on material tests, work on the power supply system, etc.), an expert system supporting the process of the selection of manufacturing materials, a system of pre-manufacture model verification, and a quality control system. On the basis of this system, devices supporting the respiratory process were designed and manufactured, with a high degree of 3D printing.

Figure 5 illustrates a plan of the proposed device (a) and its model (b). All of its elements were discussed and designed through remote access to the iS Rapid environment.

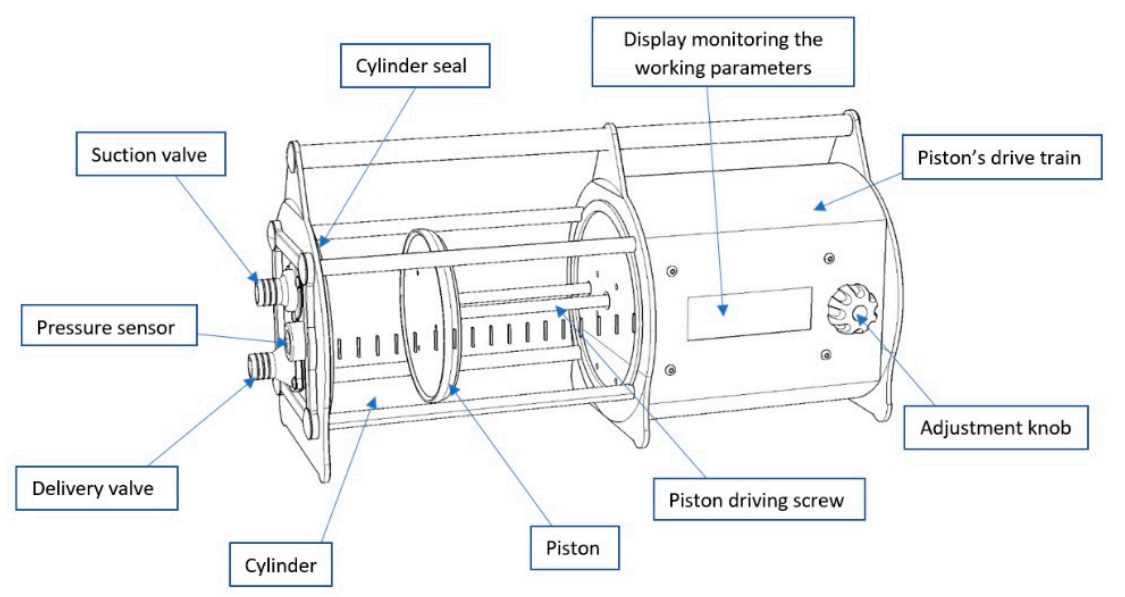

(a)

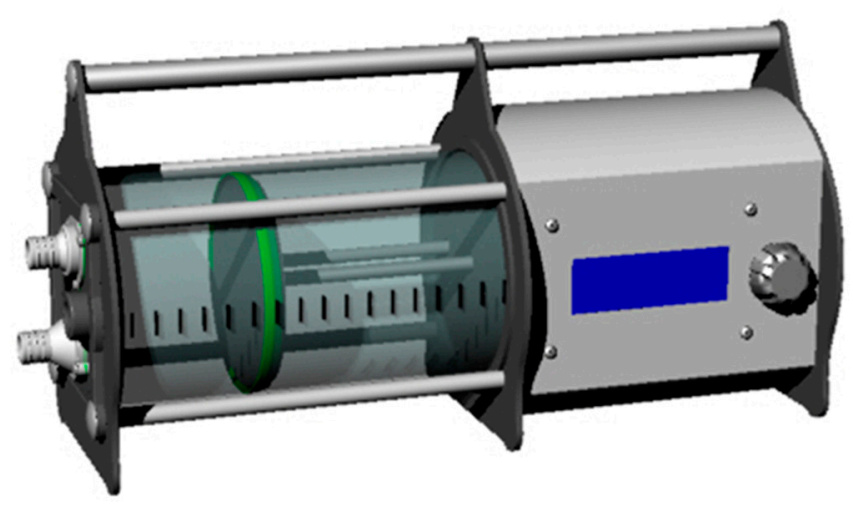

(b)

Figure 5. (a) A plan of the developed respiratory support device; (b) a model made in a CAD application.

Most of the device's components have been printed in 3D technology. Its advantage is the speed of new components, the desired durability (depending on the used material), and the possibility of sanitization due to the fact that, for instance, PET material (polyethylene terephthalate) [58] does not react chemically with such agents. A detailed description of the materials used is presented in Table 2. At the initial stage, a cylinder printout was also assumed. However, after the first tests and trials it was concluded that the printed structure introduces additional resistance (increased friction) and a much better solution would be to use glass. Glass, in general, is more hygienic, easier to 
sanitize, and is not subject to scratches during the operation of the piston, the components of which are made of TPU (thermoplastic polyurethane) [59]. TPU material has been used due to its strength and flexibility at lower temperatures, therefore, it is suitable for parts exposed to bending and compression. At this stage, once again, the iS Rapid remote working environment has proved to be a perfect fit as it enabled cooperation with glassworks located in the region and consultations during the design and manufacture of the cylinder. Additionally, at this point it should be emphasized that the model shown in Figure 2 also proved to work well, as remote verification and control was performed, followed by modifications at the level of the created digital model and the selection of technical parameters.

Table 2. Used materials.

\begin{tabular}{ccc}
\hline Name of the Element & Technology & Material Type \\
\hline Cylinder's top & 3D printing & PET \\
Cylinder's bottom & 3D printing & PET \\
Cylinder & liquation & Glass (initially PET) \\
Piston (sealer) & 3D printing & PET/TPU \\
Valves & 3D printing & PET \\
Cylinder and valve seals & 3D printing & TPU \\
Electronics casing & 3D printing & PET/ABS ${ }^{1 / P C A B S ~}{ }^{2}$ \\
Electronics (processor AT Mega, stepper & Modules & Integrated circuit \\
motor driver, pressure sensor) & Finished component & \\
Solid propeller & Finished component & \\
Nut propeller & 3D printing & PET/PCABS ${ }^{2}$ \\
Sprocket wheels &
\end{tabular}

The operation of the whole device is based on a stepper motor. The decision to use it was determined by several aspects. Primarily, stepper motors are cheap and easily accessible as opposed to pneumatic power systems. Additionally, their use is supported by the low purchase costs, their high speed, and ease of installation. Additionally, such an engine can be powered from various, easily accessible energy sources, e.g., the $12 \mathrm{~V}$ power supply of a car, power banks, etc. The most important function of a ventilator is the insertion of air, oxygen, or a properly prepared gas mixture into the lungs. Two approaches have been considered at the design stage. Firstly, in the most extreme and critical situations, in order to ensure only the supply of air, it can be taken directly from the environment and, through the pressure generated, forced into the respiratory system. The second option is to connect an external tank with a properly prepared gas mixture. The user is able to control with potentiometers both the speed of the piston as well as its stroke. The designed electronic system is responsible for the entire controlling system.

As a result of the works supported by the iS Rapid system, the device presented in Figure 6, etc. was created. 


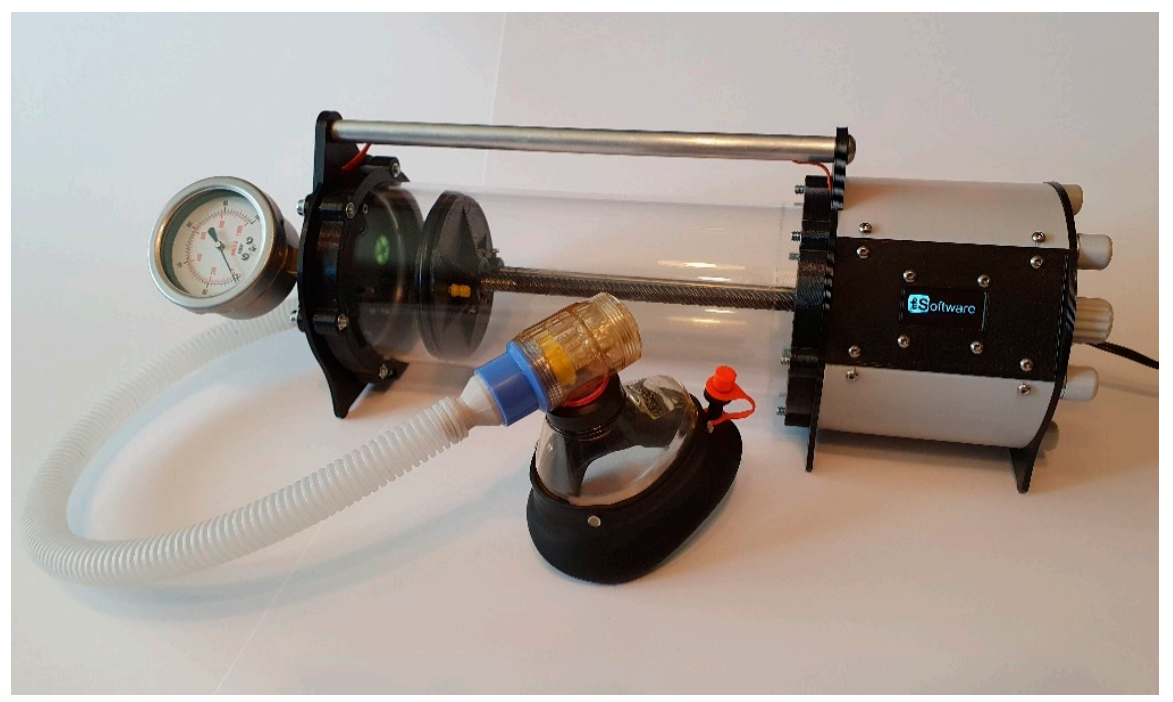

Figure 6. A photo of the finished device created with is Rapid.

\section{Conclusions}

The Industry 4.0 concept forces an unconventional approach to the implementation of all activities related to the design, manufacture, and delivery of products and services. In order to be able to integrate many processes for the collection and further more efficient use of data, available resources and human capital, it is necessary to use the newest technologies from the fields of information technology, telecommunications, automatics, artificial intelligence, etc. Naturally, the task that engineers and scientists are facing is very ambitious, and yet difficult. Therefore, numerous activities are being undertaken all over the world in order to make the concept of Industry 4.0 as broadly achievable as possible. In the time of globalization, there is vast potential for design and production resources, which are situated in various locations, often far away from one another. On the grounds of analyses of available solutions and the needs of potential customers, a model, and then the architecture of the remote prototyping system were developed. As a result of cooperation of both scientists and industry representatives, the system has been implemented in a real environment. Its potential became unexpectedly noticeable in the relation to the events of the last few weeks, which concerned the outbreak of the SARS-CoV-2 virus. These events enforced the reduction of human interaction, and thus changed the existing model of cooperation. Under these circumstances, a remote prototyping environment based on distributed design and production resources has, in many cases, become the only one available. One of the examples of using this system in this critical situation was the development of a prototype of a simple "last resort" ventilator by a team of specialists located in various remote locations. The basic assumptions of the project were to reduce costs and speed of implementation, which are very important in an epidemic. The success of this project is illustrated above all by the wide range of applications of complex rapid prototyping and production automation systems.

Further work can be outlined in at least two areas. The first one concerns the development of the remote design and manufacturing environment itself, and the second one is related to the development of a prototype breathing aid device. In the case of the system, further plans for its expansion include the integration of a wider machine park, including the operation of production robots, selected production lines, but also equipping the system with new innovative functionalities, e.g., artificial intelligence for planning, designing, and manufacturing components (in order to relieve the employees to a greater extent), integration with the virtual and extended reality environment, as well as the implementation of digital twins (a digital replica of physical objects, processes, and systems). During the works, a very important element of the system for remote control was used-the advanced coordinate and non-contact measuring techniques and methods that were integrated within the system. In the case of the so called "last resort ventilator", it is planned to carry out further works in the scope of increasing 
the efficiency of operation, among others, by testing the materials from which the ventilator will be made and their properties. It is also planned to design and equip it with additional modules, which will allow an increase in its functionality in the scope of monitoring and control of its operation, as well as control and handling of alarm calls.

Author Contributions: A.P., M.B., G.B., P.S., T.P., M.O., Ł.P. researched the literature; A.P., M.B., G.B., P.S., T.P., M.O. formulated the problems and constructed the research framework, A.P., M.B., G.B., M.O. conceived the model; A.P., M.B., G.B., P.S., T.P. developed system architecture; A.P., M.B., G.B. P.S. designed and implemented the software; A.P., M.B., G.B., P.S., T.P., M.O., Ł.P. developed a prototype; A.P., M.B., G.B., P.S., T.P., M.O., Ł.P. planned and carried out the manufacturing process; P.S., T.P. conducted tests; A.P., M.B., G.B., P.S., T.P., M.O., Ł.P. contributed to contributed to writing of this paper. All authors have read and agreed to the published version of the manuscript.

Funding: This research received no external funding.

Conflicts of Interest: The authors declare no conflict of interest.

\section{References}

1. Maresova, P.; Soukal, I.; Svobodova, L.; Hedvicakova, M.; Javanmardi, E.; Selamat, A.; Krejcar, O. Consequences of Industry 4.0 in business and economics. Economies 2018, 6, 46. [CrossRef]

2. Oleksy, M.; Budzik, G.; Sanocka-Zajdel, A.; Paszkiewicz, A.; Bolanowski, M.; Oliwa, R.; Mazur, Ł. Industry 4.0. Part, I. Selected applications in processing of polymer materials. Polimery 2018, 63, 52-56. [CrossRef]

3. Pereira, A.C.; Romero, F. A review of the meanings and the implications of the Industry 4.0 concept. Procedia Manuf. 2017, 13, 1206-1214. [CrossRef]

4. Suh, S.-H.; Shin, S.-J.; Yoon, J.-S.; Um, J.-M. UbiDM: A new paradigm for product design and manufacturing via ubiquitous computing technology. Int. J. Comput. Integr. Manuf. 2008, 21, 540-549. [CrossRef]

5. Zuehlke, D. Smart factory-towards a factory-of-things. Annu. Rev. Control. 2010, 34, 129-138. [CrossRef]

6. Zhang, Y.; Huang, G.Q.; Sun, S.; Yang, T. Multi-agent based real-time production scheduling method for radio frequency identification enabled ubiquitous shopfloor environment. Comput. Ind. Eng. 2014, 76, 89-97. [CrossRef]

7. Zhang, Y.F.; Qu, T.; Ho, O.; Huang, G.Q. Real-time work-in-progress management for smart object enabled ubiquitous shop floor environment. Int. J. Comput. Integr. Manuf. 2011, 24, 431-445. [CrossRef]

8. Putnik, G.; Cardeira, C.; Leitão, P.; Restivo, F.; Santos, J.; Sluga, A.; Butala, P. Towards ubiquitous production systems and enterprises. In Proceedings of the IEEE International Symposium on Industrial Electronics, Vigo, Spain, 4-7 June 2007; pp. 3203-3208. [CrossRef]

9. Chen, T.; Lin, Y.-C. A digital equipment identifier system. J. Intell. Manuf. 2017, 28, 1159-1169. [CrossRef]

10. Zhang, Y.; Zhang, G.; Liu, Y.; Hu, D. Research on services encapsulation and virtualization access model of machine for cloud manufacturing. J. Intell. Manuf. 2017, 28, 1109-1123. [CrossRef]

11. Masoni, R.; Ferrise, F.; Bordegoni, M.; Gattullo, M.; Uva, A.E.; Fiorentino, M.; Carrabba, E.; Di Donato, M. Supporting remote maintenance in Industry 4.0 through augmented reality. Procedia Manuf. 2017, 11, 1296-1302. [CrossRef]

12. Mazur, D.; Paszkiewicz, A.; Bolanowski, M.; Budzik, G.; Oleksy, M. Analysis of possible SDN use in the rapid prototyping process part of the Industry 4.0. Bull. Pol. Acad. Sci. Tech. Sci. 2019, 67, 21-30. [CrossRef]

13. Fuha, J.Y.H.; Lib, W.D. Advances in collaborative CAD: The-state-of-the art. Comput. Aided Des. 2005, 37, 571-581. [CrossRef]

14. Park, S.; Huh, J.-H. Effect of cooperation on manufacturing IT project development and test bed for successful Industry 4.0 project: Safety management for security. Processes 2018, 6, 88. [CrossRef]

15. Lee, S.K.; Bae, M.; Kim, H. Future of IoT networks: A survey. Appl. Sci. 2017, 7, 1072. [CrossRef]

16. Hussain, F. Internet of everything. In Internet of Things; Hussain, F., Ed.; Springer: Cham, Switzerland, 2017; pp. 1-11. [CrossRef]

17. Rahman, M.A.; Asyhari, A.T. The Emergence of Internet of Things (IoT): Connecting anything, anywhere. Computers 2019, 8, 40. [CrossRef]

18. Snyder, T.; Byrd, G. The Internet of Everything. Computer 2017, 50, 8-9. [CrossRef]

19. Fonseca, F.; Marcinkowski, M.; Davis, C. Cyber-human systems of thought and understanding. J. Assoc. Inf. Sci. Technol. (JASIST) 2019, 70, 402-411. [CrossRef] 
20. Ansari, F.; Khobreh, M.; Seidenberg, U.; Sihn, W. A problem-solving ontology for human-centered cyber physical production systems. CIRP J. Manuf. Sci. Technol. 2018, 22, 91-106. [CrossRef]

21. National Science Foundation. Available online: https://www.nsf.gov/funding/pgm_summ.jsp?pims_id= 504958 (accessed on 17 April 2020).

22. Henke, K. Rapid Prototyping modules for remote engineering applications. Int. J. Online Biomed. Eng. (iJOE) 2008, 4, 23-30.

23. Matta, A.K.; Ranga Raju, D.; Suman, K.N.S. The Integration of CAD/CAM and rapid prototyping in product development: A review. Mater. Today Proc. 2015, 2, 3438-3445. [CrossRef]

24. Luo, R.C.; Tzou, J.H.; Chang, Y.C. An Internet-based remote control and monitoring rapid prototyping system. In Proceedings of the 27th Annual Conference of the IEEE Industrial Electronics Society (IECON'01), Denver, CO, USA, 29 November-2 December 2001. [CrossRef]

25. iRise-Cooperation Platform. Available online: https://www.irise.com/ (accessed on 17 April 2020).

26. Werner, S.; Lauber, A.; Becker, J.; Sax, E. Cloud-based remote virtual prototyping platform for embedded control applications: Cloud-based infrastructure for large-scale embedded hardware-related programming laboratories. In Proceedings of the 13th International Conference on Remote Engineering and Virtual Instrumentation (REV), UNED, Madrid, Spain, 24-26 February 2016. [CrossRef]

27. Morgan, F.; O’Loughlin, D.; Audiger, J.; Boyer, Y.; Timlin-Canning, N.; Kepa, K.; Cawley, S.; Gallivan, I.; Bakó, L.; Callaly, F. Vicilogic 2.0: Online Learning and Prototyping of Digital Systems Using PYNQ-Z1/-Z2 SoC. In Proceedings of the International Symposium on Rapid System Prototyping (RSP), Torino, Italy, 4-5 October 2018. [CrossRef]

28. Canavan, D.; Callaly, F.; Boyd, A.; O'Loughlin, D.; Audiger, J.; Boyer, Y.; Timlin-Canning, N.; Bertrand, M.; Espanol, J.; Morgan, F.; et al. Audio DSP remote hardware prototyping and console creation. In Proceedings of the 29th Irish Signals and Systems Conference (ISSC), Belfast, UK, 21-22 June 2018. [CrossRef]

29. Brzoza-Woch, R.; Gurdek, Ł.; Szydło, T. Rapid Embedded Systems Prototyping-an Effective Approach to Embedded Systems Development. In Proceedings of the Federated Conference on Computer Science and Information Systems (FedCSIS), Poznań, Poland, 9-12 September 2018. [CrossRef]

30. Feng, S.; Quivira, F.; Schirner, G. Framework for Rapid Development of Embedded Human-in-the-Loop Cyber-Physical Systems. In Proceedings of the IEEE 16th International Conference on Bioinformatics and Bioengineering (BIBE), Taichung, Taiwan, 31 October-2 November 2016. [CrossRef]

31. Henke, K.; Tabunshchyk, G.; Wuttke, H.-D.; Vietzke, T.; Ostendorff, S. Using Interactive Hybrid Online Labs for rapid prototyping of digital systems. In Proceedings of the 11th International Conference on Remote Engineering and Virtual Instrumentation (REV), Porto, Portugal, 26-28 February 2014. [CrossRef]

32. Kielan, P.; Kłapyta, G. The idea of laboratory stand for rapid prototyping of robot control systems for remote operation via Internet. In Proceedings of the 15th International Workshop on Research and Education in Mechatronics (REM), El Gouna, Red Sea, Egypt, 9-11 September 2014. [CrossRef]

33. Tian, C. Virtual-prototype based network rapid development platform for pump. Trans. Chin. Soc. Agric. Eng. 2003, 3, 31.

34. Zhong, H.; Wachs, J.P.; Nof, S.Y. Telerobot-enabled HUB-CI model for collaborative lifecycle management of design and prototyping. Comput. Ind. 2014, 65, 550-562. [CrossRef]

35. 3D Printeros-Cloud 3D Printer Management and Infrastructure Platform. Available online: https://www. 3dprinteros.com/ (accessed on 17 April 2020).

36. i.materialise-3D Printing Service. Available online: https://i.materialise.com/ (accessed on 17 April 2020).

37. 3D HUBS—On-Demand Manufacturing and rApid Prototyping Platform. Available online: https://www. 3dhubs.com/ (accessed on 17 April 2020).

38. Safford, D.R.; Wiseman, M. Hardware Rooted Trust for Additive Manufacturing. IEEE Access 2019, 7 , 79211-79215. [CrossRef]

39. Pilloni, V. How data will transform industrial processes: Crowd sensing, crowdsourcing and big data as pillars of Industry 4.0. Future Internet 2018, 10, 24. [CrossRef]

40. Budzik, G. Dokładność Geometryczna Łopatek Turbin Silników Lotniczych; Oficyna Wydawnicza Politechniki Rzeszowskiej: Rzeszów, Poland, 2013.

41. Ford, S.L.N. Additive manufacturing technology: Potential implications for U.S. manufacturing competitiveness. J. Int. Commer. Econ. 2014, 6, 40. 
42. Pratt, M.J.; Bhatt, A.D.; Dutta, D.; Lyons, K.W.; Patil, L.; Siriam, R.D. Progress towards an international standard for data transfer in rapid prototyping and layered manufacturing. Comput. Aided Des. 2002, 34, 1111-1121. [CrossRef]

43. Oleksy, M.; Budzik, G.; Bolanowski, M.; Paszkiewicz, A. Industry 4.0. Part II. Conditions in the area of production technology and architecture of IT system in processing of polymer materials. Polimery 2019, 64, 32-36. [CrossRef]

44. Chua, C.K.; Yeong, W.Y.; An, J. 3D printing and bioprinting in MEMS technology. Micromachines 2017, 8, 229. [CrossRef]

45. Oleksy, M.; Budzik, G.; Kozik, B.; Gardzińska, A. Polymer hybrid nanocomposites used in Rapid Prototyping technology. Polimery 2017, 62, 3-10. [CrossRef]

46. Chua, C.K.; Leong, K.F. 3D Printing and Additive Manufacturing: Principles and Applications, 5th ed.; World Scientific: Singapore, 2017.

47. Atlam, H.F.; Walters, R.J.; Wills, G.B. Fog computing and the internet of things: A review. Big Data Cogn. Comput. 2018, 2, 10. [CrossRef]

48. Phung, X.L.; Truong, H.S.; Bui, N.T. Expert system based on integrated fuzzy AHP for automatic cutting tool selection. Appl. Sci. 2019, 9, 4308. [CrossRef]

49. Benotsmane, R.; Kovács, G.; Dudás, L. Economic, Social impacts and operation of smart factories in Industry 4.0 focusing on simulation and artificial intelligence of collaborating robots. Soc. Sci. 2019, 8, 143. [CrossRef]

50. Lee, J.; Davari, H.; Singh, J.; Pandhare, V. Industrial artificial intelligence for Industry 4.0-based manufacturing systems. Manuf. Lett. 2018, 18, 20-23. [CrossRef]

51. Villalba-Diez, J.; Schmidt, D.; Gevers, R.; Ordieres-Meré, J.; Buchwitz, M.; Wellbrock, W. Deep learning for industrial computer vision quality control in the printing Industry 4.0. Sensors 2019, 19, 3987. [CrossRef]

52. Lu, Y. Industry 4.0: A survey on technologies, applications and open research issues. J. Ind. Inf. Integr. 2017, 6, 1-10. [CrossRef]

53. Wanga, J.; Ma, Y.; Zhang, L.; Gao, R.X.; Wu, D. Deep learning for smart manufacturing: Methods and applications. J. Manuf. Syst. 2018, 48, 144-156. [CrossRef]

54. $\mathrm{Xu}, \mathrm{X}$. From cloud computing to cloud manufacturing. Robot. Comput. Integr. Manuf. 2012, 28, 75-86. [CrossRef]

55. Nassehi, A.; Newman, S.T.; Xu, X.W.; Rosso, R.S.U. Toward interoperable CNC manufacturing. Int. J. Comput. Integr. Manuf. 2008, 21, 222-230. [CrossRef]

56. Siderska, J.; Mubarok, K. Cloud manufacturing platform and architecture design. Multidiscip. Asp. Prod. Eng. 2018, 1, 673-680. [CrossRef]

57. Škulj, G.; Vrabič, R.; Butala, P.; Sluga, A. Decentralised network architecture for cloud manufacturing. Int. J. Comput. Integr. Manuf. 2017, 30, 395-408. [CrossRef]

58. Wojtyła, S.; Klama, P.; Baran, T. Is 3D printing safe? Analysis of the thermal treatment of thermoplastics: ABS, PLA, PET and nylon. J. Occup. Environ. Hyg. 2017, 14, D80-D85. [CrossRef] [PubMed]

59. Sokolowsk, W.; Metcalfe, A.; Hayashi, S.; Yahia, L.H.; Raymond, J. Medical applications of shape memory polymers. Biomed. Mater. 2007, 2, 23-27. [CrossRef] [PubMed]

60. Inberg, J.P.F.; Gaymans, R.J. Polycarbonate and co-continuous polycarbonate/ABS blends: Influence of notch radius. Polymer 2002, 43, 4197-4205. [CrossRef]

(C) 2020 by the authors. Licensee MDPI, Basel, Switzerland. This article is an open access article distributed under the terms and conditions of the Creative Commons Attribution (CC BY) license (http://creativecommons.org/licenses/by/4.0/). 